\title{
Interações em ambientes online de compartilhamento de fotografias: considerações baseadas nas perspectivas interacionista e dramatúrgica
}

\author{
Interactions in photo-sharing environments: considerations based on \\ interactionist and dramaturgical perspectives
}

José CARLOS RIBEIRO

Professor no Programa de Pós-Graduação em Comunicação e Cultura Contemporâneas da Universidade Federal da Bahia - UFBA. <icsr01@gmail.com>

VITOR BRAGA

Doutorando no Programa de Pós-Graduação em Comunicação e Cultura Contemporâneas da Universidade Federal da Bahia - UFBA. $<$ vitorbragamg@gmail.com>

\section{RESUMO}

Este artigo examina as interações observadas em ambientes online de compartilhamento de fotografias. As discussões estão centradas nas análises do exercício de performances e da construção de significados por parte dos usuários, bem como no exame da inter-relação existente entre as dinâmicas interacionais comumente observadas nestes ambientes e os referenciais identitários passíveis de serem utilizados. Para tanto, adotamos as perspectivas interacionista e dramatúrgica como referenciais teóricos para embasar as discussões propostas.

Palavras-chave: Interações; Sites de Redes Sociais; Compartilhamento de Fotografias.

\section{ABSTRACT}

This article examines the interactions observed in online photosharing environments. The discussions are focused on the analysis in the performance exercise and the construction of meanings for users, as well as the examination of the interrelationship between the interactional dynamics commonly observed in these environments and the identity references that can be used. For doing this, we chose the interactionist and dramaturgical perspectives as theoretical frameworks to support the proposed discussions.

KEYwords: Interactions; Social Network Sites; Photo-sharing. 
contexto atual da Internet tem sido fortemente marcado pelo desenvolvimento de mecanismos que visam facilitar a participação dos usuários em cenários de interação. Com a crescente popularização desses espaços digitais, observa-se de maneira frequente a emergência de processos associados às práticas de trabalho coletivo, de trocas afetivas e de construção social de conhecimentos.

Todavia, nesses ambientes, é possível perceber uma recente segmentação fomentada pelo surgimento de sites que visam essencialmente à produção e à circulação descentralizadas de conteúdos. Nestas plataformas, o que se constata é uma diversificação de mecanismos de interação e uma expansão de possibilidades relacionais ancoradas - na maioria das vezes - em eixos temáticos de discussão, articulados principalmente em torno de conteúdos (fotos, vídeos, músicas, dentre outros) compartilhados pelos usuários.

No caso dos sites de redes sociais (SRS) destinados ao compartilhamento de fotografias, percebemos que as interações ocorrem em torno de conteúdos imagéticos, através dos quais dinâmicas e articulações sociais alimentadas por discussões provenientes das páginas dos usuários se mostram em crescente processo de expansão de experiências interativas. Nesses, observamos que a possibilidade de gerenciamento dos conteúdos circulados e dos formatos que se apresentam aos usuários revela um aspecto interessante para exame: a interveniência de variáveis técnico-operacionais no processo de formatação de cenários de interação.

Trazendo essa discussão para o $F l i c k r^{1}$, a formatação e a configuração de trocas sociais parecem revelar uma característica peculiar: os usuários desse site não se apresentariam apenas como produtores de conteúdos, mas também como construtores de referenciais identitários, que serviriam de base para o desempenho de certos papéis 
no ambiente. Através da construção desses referenciais, possibilitados pela circulação de imagens e pela utilização de recursos promotores de interações (inserção de comentários, por exemplo), os usuários teriam a possibilidade de ressaltar aspectos de si mesmos que se aproximariam com as expressões de suas imagens desejadas para as situações sociais vivenciadas.

Nossa reflexão parte da premissa de que esta possibilidade ocorre por meio das performances exercidas pelos usuários nesses cenários e pela construção de significados derivados da presença de objetos que podem, de acordo com a apropriação de cada usuário, constituírem-se em elementos intervenientes nas ações ocorridas no ambiente do site. Para o desenvolvimento desta proposta, utilizamos como lentes interpretativas o Interacionismo Simbólico (Blumer, 1969; Mead, 1934), para a discussão sobre a construção de significados perante os objetos, e a Teoria Dramatúrgica (Goffman, 1986, 1999), para a reflexão sobre as performances dos indivíduos nos cenários de interação.

Em nosso entendimento, a produção e circulação de conteúdos, aliadas às particularidades técnicas disponibilizadas no ambiente, oferecem condições para a emergência de determinados comportamentos sociais entre os participantes, e estes, por sua vez, utilizam-se dessas condições para a formatação de cenários de interação que estão essencialmente imbricados aos significados negociados entre usuários e objetos presentes na situação.

\section{Interações em SRS: perspectivas interacionista e dramatúrgica}

Refletindo sobre a situação que se dispõem os atores no estabelecimento de laços nos ambientes dos SRS, na primeira seção abordamos o que se compreende aqui por construção de significados perante os objetos na interação, para, na seção seguinte, discorrermos sobre como o estudo da performance auxilia no entendimento de padrões sociocomportamentais efetivados nestes ambientes. 


\section{Na perspectiva interacionista: o significado dos objetos}

A corrente teórica do Interacionismo Simbólico (IS) investiga a dinâmica desenvolvida nas interações, principalmente no que se refere à construção de significados perante os objetos. A mesma ancora-se em uma perspectiva que considera que os objetos sociais são construídos e reconstruídos interminavelmente pelos atores.

Segundo Mead (1934), o IS entende a vida em grupo como um processo em que as pessoas, quando se encontram em diferentes situações, indicam linhas de ação umas às outras e interpretam as indicações feitas pelos outros - gerando dessa forma as bases dos comportamentos sociais sugeridos para diversas situações vivenciadas. Toda ação particular, então, seria formada em função da situação, onde certos indivíduos estariam inseridos.

No mesmo enfoque, Blumer (1969), ao discorrer sobre características importantes do IS, defende a compreensão das práticas sociais de interação por uma análise a partir de três premissas: (1) de que a natureza humana age sobre os objetos baseada no significado que estas têm para cada um; (2) de que o significado é resultado dos - ou é construído a partir dos - processos de interação social; e (3) que esses significados são manejados e modificados através de um processo interpretativo, utilizado por cada um.

Assim, tendo como base essas três premissas, a posição do IS é de que os significados que as coisas têm para os seres humanos são centrais para compreender o comportamento. Neste entendimento, a mais importante forma de interação ocorre sempre no plano simbólico. Essa interação simbólica é a aquela em que os participantes respondem à ação dos outros em função do significado dessas ações (Blumer, 1969). E é esse elemento de significado construído que vem introduzir, nos contatos e ações entre indivíduos, três processos fundamentais: (1) a elaboração de indicações, (2) a interpretação das indicações e (3) a formulação de respostas resultantes das interpretações. 
Para o IS, os significados não são intrínsecos aos objetos e nem provêm de elementos psicológicos do indivíduo, mas surgem a partir do processo de interação entre as pessoas. As ações operam para definir os objetos para as pessoas. Logo, o IS vê o significado como um produto social, criado nas e por meio das atividades das pessoas enquanto interagem.

Como ressalta Mead (1934), "objeto" é tudo que é designado ou referido como tal na dinâmica geradora das trocas sociais. A natureza do objeto é, portanto, constituída pelo significado que tem para cada pessoa ou grupo; tal significado não é intrínseco ao mesmo, mas decorre da forma como a pessoa se mostra inicialmente preparada para agir em relação a ele e, consequentemente, redimensioná-lo. Revela-se, assim, a existência de um processo de interpretação contínuo pelo qual se formata o sentido de maneira essencialmente dinâmica.

Trazendo a discussão para os ambientes SRS, é possível inferir que a configuração e a disposição dos objetos presentes nestes cenários - derivadas, sobretudo, das especificidades dos recursos e dispositivos técnico-operacionais disponíveis nas plataformas - são fundamentais na formatação dos significados construídos, e consequentemente nos modos de agenciamento de modelos e de práticas sociais.

Dessa forma, o surgimento de SRS tem apresentado questões referentes às particularidades da interação e das suas possíveis consequências no contexto em que estão situados os indivíduos e os objetos. Nessa perspectiva, ao tratar das correntes teóricas adotadas para a compreensão de processos comunicativos, Araújo (2007) considera o interacionismo como uma perspectiva importante, tendo em vista o entendimento do contexto da ação em que se dispõem os envolvidos, considerando as particularidades inerentes a cada contexto analisado.

Refletindo sobre situações sociais presentes nos ambientes da Internet, diversos autores (Fernback, 2007; Boyd, 2002) - dentre outros - buscaram compreender 
a interação mediada pelos SRS através da perspectiva do IS. O que se destaca nesses trabalhos, de maneira geral, é a ênfase colocada nos papéis dos conteúdos compartilhados e nas funcionalidades - derivadas dos recursos e dispositivos técnicooperacionais disponibilizados nos ambientes - como fatores determinantes no processo de construção de significados por parte dos usuários. A argumentação reside, portanto, na importância da centralidade de conteúdos - fotografias, vídeos, músicas, textos (Fernback, 2007) -, e na presença de recursos complementares aos conteúdos postados pelos usuários - comentários, legendas, tags e georreferências -, que propiciam um processo contínuo e dinâmico de construção de significados perante esses objetos mediadores, assim como de condições situacionais particulares para a emergência de interpretações no plano simbólico e de referenciais identitários.

Conforme aponta Boyd (2002), o indivíduo tende a ajustar informações referentes à sua identidade de acordo com as reações dos interlocutores. Nesse sentido, as possíveis discussões com outros usuários interessados na mesma temática, assim como a tendência ao compartilhamento de conteúdos de interesse para determinados grupos de usuários, ambas facilitadas pelos recursos disponíveis, mostram-se como práticas que viabilizam a formatação de cenários de interação. Estas práticas, por sua vez, se revelam como geradoras de referenciais identitários que servem de base para as expressões e os comportamentos sociais nos sites (Ribeiro; Braga, 2009).

Considerando os aspectos levantados anteriormente é que entendemos que as identidades dos usuários estão em processo contínuo de formatação através das experiências vivenciadas nas diversas situações promovidas, situações estas geradoras de sentidos, que, por sua vez, são agenciados no interior de processos de produção e de recepção de conteúdos. Assim, observa-se nesses sites uma ambiência de significações em que operam forças de demarcação de conteúdos, dinamizadoras e produtoras de interações sociais. 


\section{Na perspectiva dramatúrgica: as performances dos usuários}

Goffman (1999) defende a ideia de que o homem em sociedade, de forma consciente ou não, sempre utiliza uma atitude performática para se mostrar aos demais, empregando certas técnicas para a sustentação de seu desempenho, tal qual um ator que desempenha o papel de um personagem diante do público. Assim como os interacionistas, reconhece a relevância da dimensão coletiva da ação social nos cenários, sem renunciar à ênfase na iniciativa dos indivíduos no contexto da ação.

A Teoria Dramatúrgica entende que a performance dos indivíduos deve ser compreendida a partir de um olhar relacional. Olhar este que busca dar conta das interações, por meio das quais se colocam em jogo indivíduos, significados e contextos. Um indivíduo participando de uma interação apresenta-se engajado em uma performance mais ou menos qualificada (Argyle; Kendon, 1972). Seu comportamento mostra-se direto, adaptativo, longe de ser automático, ainda que pareça ser construído com elementos que se tornam automatizados. Partindo desse ponto, a atitude performática é trabalhada por Goffman (1986) no sentido em que pode não só determinar como uma mensagem deve ser entendida, mas também indicar quais tipos de mensagens podem ser esperados em uma interação. Assim, estruturas de expectativa se formam em qualquer situação, com o intuito de organizar o discurso e orientar os envolvidos em suas atividades sociais.

Nesta perspectiva, as pessoas criam quadros para sua experiência (Goffman, 1986). Tais quadros são construídos a partir de performances: arranjos que convertem um ou mais indivíduos em performers e outros em espectadores. Em adição a isto, aqueles que exercem performances criam enquadramentos primários nos cenários de interação; ou seja, definem a situação de modo a possibilitar adesão a alguns parâmetros já incorporados pelos atores sociais. 
Desta forma, os sujeitos buscam, em suas performances, incorporar valores reconhecidos pela sociedade. Na presença de outros indivíduos, o performer geralmente inclui sinais que acentuam e configuram fatos confirmatórios que, sem isso, poderiam permanecer despercebidos ou obscuros. Assim, o indivíduo se mostra propenso a abandonar ou esconder aspectos não compatíveis com esses propósitos.

No ambiente de interações dos SRS, Simões (2010) entende que indivíduos estão realizando determinadas trocas simbólicas de modo a influenciar nas suas performances. Boyd (2002), por sua vez, afirma que existem nos SRS menos elementos de emissão expressivos, pois estes estão relacionados exclusivamente àqueles veiculáveis por formas verbal e visual, havendo portanto uma preponderância da informação deliberadamente transmitida, através de posts e comentários efetivados pelos indivíduos; fato este que acarretaria consequências à classe de interação estabelecida. A partir de outra perspectiva, Braga (2008) afirma que os sujeitos encontram menos obstáculos - ou obstáculos de outra ordem - ao tentar manejar a impressão causada através de tentativas de controle da informação fornecida.

É possível também verificar que, em dinâmicas verificadas nos ambientes digitais, os desempenhos de papéis não se apresentam rigorosamente estabelecidos (Ribeiro, 2005). Com isto, o indivíduo se encontra em uma situação particular que promove uma ampliação das possibilidades de gerenciamento e de efetivação de comportamentos nas circunstâncias determinadas e nas expectativas criadas por cada papel nas situações vivenciadas.

Considerando as reflexões acerca desse aspecto, entende-se de maneira geral que a arquitetura subjacente ao ambiente dos SRS não fornece formas de obtenção de feedback e contexto semelhantes aos quais os indivíduos tradicionalmente se engajam em ambientes de interação face a face. Ou seja, com possibilidades - ampliadas ou reduzidas - de gerenciamento do perfil por meio de diversos recursos disponíveis, as 
expressões identitárias formuladas pelos usuários passam por processos particulares de construção.

Ciente dessas práticas associadas às performances em ambientes da Internet, autores como Döring (2002) e Donath (1999) demonstram que a personalização é uma condição necessária para as interações entre esses usuários; é uma forma de configurar a identidade que interage com os demais usuários. Assim, a apropriação de recursos de comunicação mediada por computador apresenta-se constantemente influenciada pela performance dos usuários, tornando a situação reconhecível como um espaço individual. É o caso de redes de compartilhamento de conteúdos: dentro das possibilidades do sistema, os recursos são utilizados para apresentar as últimas "atualizações do self2" (Döring, 2002).

\section{Interações no Flickr}

Buscando identificar características associadas ao fenômeno de compartilhamento de fotografias por meio de SRS, Mason e Rennie (2008) destacam que a possibilidade de classificar as fotos em álbuns, a descrição das fotos por meio de anotações (como títulos, legendas ou tags), o fornecimento de várias exibições (tais como thumbnails e slideshows) e a inserção de comentários diversos são práticas que facilitam a emergência de um meio participativo, onde os usuários estão ativamente criando, apreciando e distribuindo informações, e também de um ambiente propício à existência de trocas interacionais.

Em uma pesquisa acerca do estabelecimento de laços entre usuários no ambiente do Flickr, Cox, Cloug e Marlow (2008) identificaram que a melhor forma de se explicar o volume de interações que cada fotografia pode exercer é relacionar o objeto diretamente ao tamanho da rede social do usuário que o postou - mais do que a valores estéticos atribuídos às fotografias por um determinado grupo ou pessoa. Paralelo a essa 
constatação, Lerman e Jones (2007) compreendem que as fotografias de usuários com uma ampla rede de contatos seriam mais suscetíveis à difusão - recebendo destaque no mecanismo de busca, por exemplo.

Em uma análise das interações desses usuários, Miller e Edwards (2007) mostram que, para alguns, o Flickr oferece suporte a um diferente conjunto de práticas interacionais por meio das fotografias, ao propor um novo paradigma para os fotógrafos, no qual sua reputação e sua visibilidade seriam construídas com a intensidade do envolvimento dos demais usuários, por meio de funcionalidades presentes no site.

Já com relação a possíveis usos sociais do site, a pesquisa de House (2009) destaca quatro modelos: (1) dispositivo de memória para a construção narrativa do indivíduo; (2) forma de autorrepresentação; (3) modo de criação relacional, de um sentido de união, de sociabilidade; e (4), por fim, como possibilidade de mostrar o trabalho artístico de alguém, numa espécie de "exposição sociável".

Considerando as pesquisas acerca das interações proporcionadas pelo Flickr (Pissard, 2007; Prieur, 2007; Lerman; Jones, 2007; House, 2009), percebemos que a grande maioria é oriunda predominantemente da perspectiva centrada na Análise de Redes Sociais (ARS) ${ }^{3}$, e identificam questões inerentes às interações através de métodos de análise quantitativa. Essas pesquisas de campo acerca do site se detêm principalmente na detecção de como os recursos presentes no site podem intervir na interação no que diz respeito à quantidade de uso, ao período de tempo etc. Estas enfocam, então, a estrutura mais do que as partes e as interconexões entre elas, em uma tentativa de observar os padrões que unem os elementos no site - correlações entre o uso de recursos por redes de usuários.

Nesse sentido, percebe-se nessa literatura a ausência de uma compreensão sobre como é possível analisar as interações tendo em vista uma abordagem do fenômeno que enfoque relações entre os atores, e em especial, que possa compreender as interações 
de modo a examinar como os significados são construídos coletivamente, através de um processo interpretativo. Propomos, assim, auxiliar nessa reflexão, ao trazer uma discussão sobre os usuários do Flickr fundamentada em uma microssociologia das interações - esta caracterizada pela busca de compreensão dos métodos utilizados pelos indivíduos enquanto desempenham seus diferentes papéis.

\section{Reflexões na perspectiva interacionista}

Em conformidade com os pontos levantados e tendo em vista os aspectos que podem ser perceptíveis nas pesquisas que abordam a corrente interacionista, é que propomos que os objetos - dispositivos e recursos disponíveis nas páginas dos SRS circulados entre os usuários podem ser interpretados como produtos sociais formados e transformados através de um processo de (res)significação constante, ocorrido a partir das interações sociais efetivadas, e dos procedimentos de gerenciamento de características identitárias.

Isto ocorreria também no ambiente de compartilhamento de conteúdos do Flickr, pois, como diz Blumer (1969) a respeito da natureza da ação humana, o indivíduo se confronta com um ambiente no qual deve interpretar a fim de agir e programar linhas de ação a partir de suas interpretações. As respostas dos outros, assim, são apreendidas e configuram os comportamentos posteriores do indivíduo. Isto significa, a princípio, que a conduta do participante não pode ser compreendida ou explicada, exceto em termos da interação e, segundo, que a ação conjunta dos participantes deve ser vista como um produto de sua interação e não uma criação derivada unicamente de uma estrutura social.

Como observado em reflexão anterior (Ribeiro; Braga, 2009), seja pelas linhas de ação interpretadas e adotadas a partir das ações dos outros, ou pelos procedimentos de ocultação e ampliação de características pessoais, é possível constatar um processo 
de negociação social, que estaria sendo dinamizado e complexificado por meio dos significados construídos perante os objetos circulados neste cenário de interação.

Dessa forma, os usuários - que são também os promotores de conteúdo ${ }^{4}$ - são percebidos como sujeitos sociais cuja realidade é composta por uma pluralidade de significados construídos (Reule, 2007), modo pelo qual se adaptam ao cotidiano e se vêem inseridos nesses ambientes. Assim, as atividades de indivíduos em redes sociais - a exemplo do Flickr - incluem a produção organizada de conteúdos; sendo esta criada seguindo determinados objetivos, e direcionada para determinados públicos. São incorporações de sentidos compartilhados, gerados por essas redes.

Então, ainda que, porventura, dado conteúdo possa receber maior ênfase, de acordo com o que se pretenda compartilhar nesses ambientes, defendemos aqui que outros mecanismos presentes - legenda, título ou comentário, por exemplo - possam alterar a tônica das discussões que permeiam os ambientes.

O Flickr parece acentuar a proposta de compartilhamento de conteúdos como forma do usuário engajar-se em um processo interativo, quando em sua página inicial dá ênfase aos dizeres: "Compartilhe sua vida em fotos".

Fig. 1 - Página inicial do site Flickr ${ }^{5}$

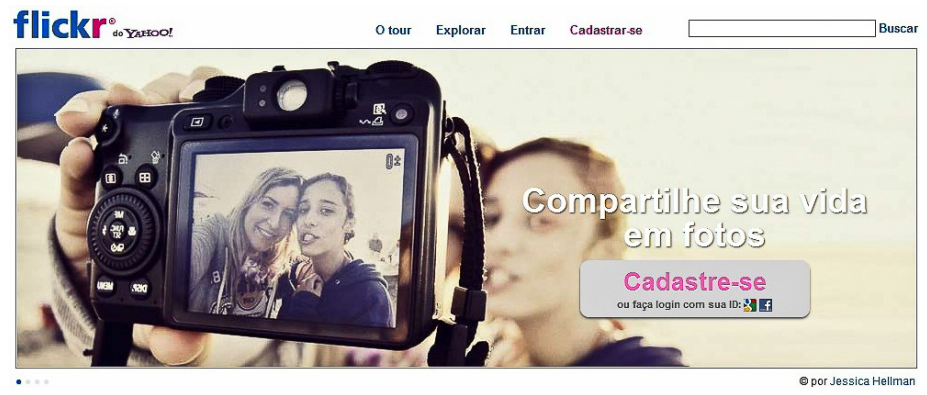

Fazer upload Mais formas de ter seus fotos online. Há várias maneiras de fazor upload para o
Flicks - através da Web, de seu dispositivo móvel, via e-mail ou através de seus aplicatives de foto favoritos.

四 圆

\section{Descubra}

o que está acontecendo ao seu redor. Acompanhe as fotos do amigos o paticippo con
comentários \& notas. Adicione ifformaģ̋es importantes como tags, localizacăoa \& pessoas na foto.

红回四
Compartilhar suas fotos onde quer que você esteja. Faça o upload de suas fotos uma única vez no
Flickre e compartihlh-as com facilidade e segurança no Facebook, Twitter, email, Blogss e muito mais.

Q0.0. 
Como se vê na Figura 1, a frase estimula um tipo de engajamento do usuário que auxilia a construção de repertórios visuais; repertórios estes que aparecem dispostos no ambiente, através das páginas personalizadas. Entendendo dessa maneira, podemos ressaltar que a circulação e o compartilhamento de conteúdos, enfaticamente estimulados pelo site, assim como os prováveis feedbacks (ou mesmo, apenas as expectativas criadas em torno deles) feitos pelos demais usuários, servem de base para formação de referenciais identitários, que, por sua vez, indicam e reforçam os comportamentos sociais posteriores. Conforme aponta Boyd (2002), o indivíduo busca sempre ajustar informações referentes à sua identidade de acordo com as reações dos demais indivíduos com os quais está interagindo.

Desta forma, as prováveis discussões com outros usuários parecem se constituir como uma importante finalidade para o hábito de se criar contas e se postar conteúdos, bem como de se ingressar nas redes de contatos daqueles possuidores de interesses semelhantes.

Em relação à construção do significado, consideramos que os recursos disponibilizados no site (comentários, marcações, tags etc.) operam intermediando as relações entre usuários. São as apropriações destes recursos que, através de um processo interpretativo, geram significados constituintes dos cenários de interação (as páginas dos usuários). Processo este feito por cada indivíduo envolvido na ação. Nesse sentido, considerando a perspectiva interacionista e a análise aqui empreendida, deve-se salientar que os recursos se apresentam como objetos intervenientes nas interações e como tais são necessários para a formatação dos ambientes interativos. Entendemos dessa forma porque, assim como disse Mead (1934), a designação “objeto” engloba o que é considerado como tal, pelos indivíduos, na dinâmica geradora das trocas sociais.

Tomando como observação o fato desses recursos serem importantes nas interações, entendemos que estes só são selecionados pelos usuários se deles forem extraídas 
trocas de conteúdo simbólico. Os recursos são, assim, produtos sociais compartilhados, formadores e transformadores dos processos interacionais, uma vez que, por intermédio deles, os usuários tomam consciência do ambiente e da situação em que se encontram e programam suas ações baseadas nas interpretações dos mesmos. A perspectiva interacionista, então, contempla a existência de um processo de interpretação pelo qual se formata o sentido de maneira dinâmica e contínua.

O sentido, portanto, é introduzido de modo que a resposta às ações de cada usuário ocorre em termos de como essas ações podem ter um significado - o que a ênfase pela utilização de determinados recursos pode suscitar na interação simbólica. Nesse sentido, nas páginas dos usuários, os significados estão sendo construídos sempre coletivamente, mas através da interpretação de cada participante.

\section{Reflexões na perspectiva dramatúrgica}

Conforme comentado, a performance do usuário ocorre de maneira predominante através da disponibilização de informações do indivíduo nos posts e nos comentários feitos por eles para seus contatos (Boyd, 2002), processo que pode se apresentar de forma bastante fluida. A cada nova atualização, o usuário desenvolve uma atitude performática, revelando traços de si e dando aos outros - seus contatos ou outros usuários que porventura venham a visualizar as informações circuladas - a percepção de como pretende ser representado, ainda que esta intenção possa não vir a condizer com a forma na qual os outros efetivamente lhe percebam. Entendemos, dessa maneira, a interação entre os usuários como uma performance, exercida de modo a causar uma impressão e, por isto, sensivelmente influenciada pelo ambiente e pela audiência respectiva.

Nesse sentido, é importante perceber como a performance do usuário pode formatar um enquadramento primário da situação. Com base nas ideias de 
Goffman (1986), postulamos aqui que ao exercerem as performances alicerçadas sobre sua matriz de interesses no site, os usuários também indicam performances a serem exercidas em suas páginas - ainda que estas não se insinuem de forma obrigatória.

Além de um enquadramento primário operar nos cenários de interação, outro aspecto interessante para análise é que, mesmo não havendo regras pré-estabelecidas ${ }^{6}$ rigorosas, os usuários costumam interagir por meio de performances que não perturbem a ordem em ambientes específicos - atuando geralmente através de comentários não ofensivos, buscando "favoritar" ou inserir tags que possam facilitar a criação de uma memória coletiva (Aquino, 2008), dentre outras ações construtivas observadas neste processo.

Considerando essa interveniência da mediação, ressalta-se que a compreensão da performance dos indivíduos, nessa perspectiva, deve ocorrer a partir de um olhar relacional. Olhar este que busca dar conta das interações - por meio das quais se coloca em jogo indivíduos, objetos, significados e contextos.

Por meio desse olhar, percebe-se que a identidade representada pelo usuário se faz visível a partir de estratégias de negociação de sua aparência, a qual se ancora nos traços de si revelados para finalidades diversas. Com efeito, usuários interessados em interagir com uma determinada audiência adotam tal postura; então, como já dito anteriormente, estes geralmente buscam interagir a partir de ações que esperam ser bem interpretadas pelos outros.

A partir das argumentações expostas nessa seção, procuramos entender como os conteúdos circulados nesses ambientes são produtos sociais formados e transformados através de um processo de apropriação constante, ocorrido a partir das interações sociais efetivadas e por meio das performances de cada usuário envolvido. 


\section{Comentários finais}

Defendemos neste artigo que, em sites de redes de compartilhamento de fotografias, os usuários adotam referenciais identitários de acordo com as articulações e situações sociais promovidas e vivenciadas. Partimos do princípio de que os usuários exercem performances de modo a criar perfis baseados em seus interesses no site; nesse caso, eles seguem padrões de interação e, assim, buscam mantê-los na ação com seus interlocutores. Ainda, ressaltamos que esses usuários estão construindo significados através de processos de apropriações que são condicionados pelas características e particularidades dos recursos e dispositivos técnico-operacionais presentes no ambiente.

Considerando estes aspectos, salientamos a necessidade de compreender os modos pelos quais os usuários constroem referenciais identitários e adotam certas práticas sociais visando mantê-los nos cenários de interação, ou seja, nas páginas respectivas. Com efeito, uma compreensão aqui levantada é de que o processo de construção das identidades dos usuários sofre interveniência tanto dos feedbacks emitidos pelos demais usuários (visualizados através de comentários, por exemplo), quanto das expectativas geradas a respeito destes.

Em síntese, podemos afirmar que as análises que visam compreender o processo de formação de cenários de interação em sites de compartilhamento de conteúdos, em particular os de fotografias, ao focarem suas reflexões sobre o exercício das performances e sobre a construção de significados, ganham uma dimensão particular, haja vista que trazem elementos interpretativos que ajudam a pensar a inter-relação existente entre as dinâmicas interacionais observadas nestes ambientes e as referências identitárias utilizadas pelos usuários e advindas desses processos. Estas foram nossas intenções neste trabalho. 


\section{REFERÊNCIAS}

ARGYLE, Michael; KENDON, Adam. The experimental analysis of social performance. In: LAVER, John; HUTCHESON, Sandy. Communication in face to face interaction. Harmondsworth: Penguin Books, 1972.

AQUINO, Maria Clara. A folksonomia como hipertexto potencializador de memória coletiva: um estudo dos links e das tags no de.licio.us e no Flickr. Liinc em Revista, Rio de Janeiro, v. 4, n. 2, p. 303-320, set. 2008.

ARAÚJO, Carlos. Correntes teóricas de estudo da comunicação. Verso e Reverso: Revista da Comunicação, Porto Alegre, v. 1, n. 46, p. 1-15, mar. 2007.

BLUMER, Herbert. Symbolic interactionism: Perspective and method. New Jersey: Prentice-Hall, Inc., 1969.

BOYD, Danah. Faceted Id, Entity: Managing representation in a digital world. Tese (Doutorado em Media Arts and Sciences) - Massachusetts Institute of Technology, MIT, Cambridge, 2002.

BRAGA, Adriana. Usos e consumo de meios digitais entre participantes de weblogs: uma proposta metodológica. In: PRIMO, Alex; OLIVEIRA, Ana C.; NASCIMENTO, Geraldo C.; RONSINI, Veneza M. (orgs.). Comunicação e Interações. Porto Alegre: Sulina, 2008.

COX, Andrew; CLOUGH, Paul; MARLOW, James. Flickr: a first look at user behaviour in the context of photography as serious leisure. Information Research. Suécia, v. 13, n. 1, mar 2008.

DONATH, Judith. Identity and Deception in the Virtual Community. In: KOLLOCK, Peter; SMITH, Marc (orgs.). Communities in Cyberspace. Nova York: Routledge, 1999.

DÖRING, Nicola. Personal Home Pages on the Web: A Review of Research. Journal of Computer Mediated Communication, Indiana, v. 7, n. 3, abr. 2002.

FERNBACK, Jan. Beyond the diluted community concept: a symbolic interactionist perspective on online social relations. New Media \& Society, Nova York, v. 9, n. 1, p. 49-69, fev. 2007.

GOFFMAN, Erving. A representação do eu na vida cotidiana. Petrópolis: Vozes, 1999.

GOFFMAN, Erving. Frame Analysis: An essay on the organization of the experience. Massachusetts: Northeastern University Press, 1986.

HOUSE, Nancy Van. Collocated photo sharing, story-telling, and the performance of self. International Journal of Human-Computer Studies, Nova York, v. 67, n. 1, pp. 1073-1086. mai 2009.

LERMAN, Kristina; JONES, Laurie. Social Browsing on Flickr. Anais da International Conference on Weblogs and Social Media. Colorado: Universidade de Maryland, 2007. p. 1-4.

MASON, Robin; RENNIE, Frank. E-learning and social networking handbook. Nova York: Routledge, 2008. 
MEAD, George. Mind, self and society: From the Standpoint of a Social Behaviorist. Chicago: The University of Chicago Press, 1934.

MILLER, Andrew; EDWARDS, Keith. Give and Take: A Study of Consumer Photo-Sharing Culture and Practice. Anais da Conferência Computer/Human Interaction. California: San Jose Convention Center, 2007. p. 347-356.

PISSARD, Nicolas; PRIEUR, Christophe. Thematic vs. social networks in web 2.0 communities: A case study on flickr groups. Anais da Algotel Conference. Ile d'Oléron: Centre CNRS, 2007. p. 1-4.

REULE, Danielle Sandri. De máscaras e espetáculo: formas de construção do sujeito pós-moderno virtual. In: XXX Congresso Brasileiro de Ciências da Comunicação, 2007, Santos. Anais do XXX Congresso Brasileiro de Ciências da Comunicação. Santos: Unversidade Católica de Santos, 2007. p. 1-13.

RIBEIRO, José Carlos. Múltiplas identidades virtuais: a potencialização das experiências exploratórias do "Eu". Contracampo, Niterói, v. 12, n. 1, p. 171-184, dez. 2005.

RIBEIRO, José Carlos; BRAGA, Vitor. Compartilhamento de fotografias na web: reflexões a partir da perspectiva do interacionismo simbólico. In: III Simpósio Nacional da ABCiber, 2009, São Paulo. Anais do III Simpósio Nacional da ABCiber. São Paulo: Escola Superior de Propaganda e Marketing (ESPM), 2009, p. 1-13.

SIMÕES, Paula. A centralidade da experiência na constituição das representações: contribuições interdisciplinares para o campo da comunicação. E-Compós, Brasília, v. 13, n. 1, p. 1-17, jan. 2010.

\section{NOTAS}

1 SRS que possui como funcionalidade principal o compartilhamento de fotografias. Disponível em: $<$ http://www.flickr.com/>.

2 Diz respeito a "si mesmo", no tocante ao conhecimento que um indivíduo tem sobre si próprio.

3 Conjunto de conceitos operacionais, baseado em modelos estatísticos, para a compreensão de dinâmicas de redes sociais.

4 Neste caso, os usuários cadastrados em sites de rede sociais que inserem conteúdos para que internautas possam observar e com eles interagir.

5 Fonte: <http://www.flickr.com>.

6 Vale ressaltar que o Flickr, no mesmo sentido de manter a boa convivência, também possui regras de uso (ver: <http://www.flickr.com/guidelines.gne>). 